\title{
A Inserção do Estagiário na escola e o Cuidado de si de Michel Foucault
}

\author{
Jéssica Coimbra Padilha'
}

\section{Resumo:}

Este artigo apresenta o conceito de cuidado de si de Michel Foucault visando relacioná-lo com a experiência de estágio na escola. Foucault empreende a formulação do conceito de cuidado de si a partir dos gregos, considerando o sentido da expressão "o eu do ser em formação". Este emerge como um preceito fundamental do ponto de vista filosófico, mas significa também uma continuidade técnica dessa temática sobre "ocupar-se consigo mesmo". Tendo em vista isso, o cuidado de si exige uma visão crítica em relação a si mesmo, fazendo um papel corretivo, o que torna-se de extrema importância na prática docente, ainda mais por estarmos diretamente relacionados com os alunos que são adolescentes, e é nessa etapa que estes começam a pensar e a conversar sobre o conhecimento de si mesmo, sobre como guiar e como conduzir a vida. Por esse viés, temos uma dupla dimensão: a reflexão do estagiário com vista ao conceito de cuidado de si (relação mestre-discípulo) para com o aluno que está aprendendo a cuidar de si. O problema que move as reflexões aqui é o seguinte: é possível despertar o cuidado de si nos alunos e a si mesmo?

Palavras-chave: cuidado de si; adolescente; formação do eu.

\section{La inserción del pasante en la escuela y el cuidado de sí de Michel Foucault}

\begin{abstract}
Resumen:
Este artículo introduce el concepto de cuidado de sí de Michel Foucault con el objetivo de relacionarlo con la experiencia de la pasantía en la escuela. Foucault emprende la formulación del concepto de cuidado de sí a partir de los griegos considerando el sentido

${ }^{1}$ Graduada em Filosofia Licenciatura plena pela Universidade Federal de Santa Maria. Graduanda do curso de Teatro Licenciatura na Universidade Federal de Santa Maria. Educadora de Filosofia no Pré-Universitário Popular Alternativa. Mestranda em Filosofia na Universidade Federal de Santa Maria - UFSM. E-mail: coimbrajee@hotmail.com
\end{abstract}


de la expresión "el yo del ser en formación". Este emerge como un precepto fundamental del punto de vista filosófico, pero significa también una continuidad técnica de esa temática sobre "ocuparse con sí mismo". Partiendo de eso el cuidado de sí requiere una visión crítica en relación a sí mismo, realizando un papel correctivo, que se percibe como extremadamente importante en la práctica docente, aún más porque estamos directamente relacionados con los estudiantes que son adolescentes, y es en este nivel que ellos empiezan a pensar y hablar sobre el conocimiento de sí mismo, sobre la forma de guiar y conducir la vida. Por este sesgo, tenemos una doble dimensión: la reflexión del pasante considerando el concepto de cuidado de sí (relación maestro - discípulo) hacia el estudiante que está aprendiendo a cuidar de sí mismo. El problema que mueve las reflexiones aquí es el siguiente: ¿̇es posible despertar el cuidado de sí en los alumnos y en sí mismo?

Palabras clave: cuidado de sí; adolescente; formación del yo.

\section{Introdução}

"A partir da ideia de que o indivíduo não nos é dado, acho que há apenas uma consequência prática: temos que criar a nós mesmos como uma obra de arte". (Michel

Foucault)

Em um curso intitulado "A hermenêutica do sujeito" (1982), Michel Foucault (1926 -1984) aborda o tema do cuidado de si. Este conceito retoma o que tinha sido tratado no ano anterior, no curso "Subjetividade e verdade", quando Foucault iniciou suas pesquisas sobre os modos do conhecimento de si. Para isso, adotou como fio condutor as "técnicas de si", isto é, procedimentos empregados na fixação da identidade, graças à relação de domínio de si e conhecimento de si. O filósofo interessou-se pela técnica de si para abordar uma história da subjetividade, sendo esse o motivo do curso, que tem início com a questão das relações entre subjetividade e verdade.

Nas primeiras aulas do curso, Foucault trabalhou a relação entre a filosofia e a espiritualidade, alcançando e analisando o conceito de cuidado de si, bem como o princípio de "conhece-te a ti mesmo" em Platão. O tema do cuidado de si, 
ou para ser mais preciso "ocupar-se consigo mesmo", aparece no diálogo Alcebíades de Platão associado com a questão do exercício do poder político pelos jovens atenienses. Platão questiona a autoridade conferida aos jovens nobres pelo simples pertencimento financeiro e se pergunta sobre quem deveria ser 0 governante e quais habilidades deveria possuir. $O$ desvio da questão política para o cuidado de si acontece quando Sócrates sustenta a necessidade de ocupar-se consigo mesmo antes de governar os outros.

Foucault analisou com muita atenção a passagem de Alcibíades colocando em pauta a questão: "que significa a expressão cuidar de si mesmo?" Quando o homem cuida de siẹ No desenvolvimento do diálogo, Sócrates afasta a ideia de cuidarmos de algo material, o que poderia ser, por exemplo, uma roupa, panela ou um utensílio qualquer e afirma que "não cuidas de ti mesmo quando cuidas de algo que te pertence". E mais, Sócrates afirmava que se não conhecermos a nós mesmos, não poderemos governar os outros.

Com base nisso, o cuidado de si funcionava como um fio condutor, que ia realizando-se como uma espécie de "exercício filosófico", tendo com esse estudo possibilitado um olhar bastante enriquecedor para a subjetividade e a verdade. De modo geral, Foucault pretendia demonstrar como a expressão "ocupar-se consigo mesmo" estendeu-se por toda a conduta racional, numa relação entre moral e vida filosófica. Esse princípio partia efetivamente do personagem Sócrates, uma vez que esse instigava o outro a se ocupar consigo mesmo. Ele era o mestre do cuidado de $s^{2}$. A noção de cuidado de si é entendida por Foucault como um preceito de base filosófica e moral não só em Sócrates, mas em toda moral filosófica antiga.

Nesse escrito, porém, não adentraremos de forma minuciosa e detalhada a toda reflexão de Foucault com relação ao cuidado de si, tampouco a relação de poder de um tipo de sujeito, mas a intenção é problematizar o cuidado de si, tendo em vista a experiência de estágio realizada na escola, no período de julho a dezembro de 2015, apropriando-se desses elementos e do conceito de cuidado de si para refletirmos sobre os sujeitos envolvidos. Tendo em vista a afirmação de que "A partir da ideia de que o indivíduo não nos é dado, acho que há apenas uma

2Essa expressão não refere-se ao cuidado com o corpo, mas ocupar-se com nós mesmos. 
consequência prática: temos que criar a nós mesmos como uma obra de arte" (FOUCAULT, 1982), no tocante a esse escrito, é que propormos uma reflexão por dois caminhos.

O primeiro diz respeito à busca do aperfeiçoamento da prática docente, uma vez que esse deve ser crítico de si; e a segunda dimensão a abordar corresponde ao aluno adolescente, que ainda não cuida de si, mas que está aprendendo a cuidar-se, ou seja, o conhecimento de si como um ser humano, do ponto de vista social, político, psicológico é muito incipiente frente a tantas mudanças nessa fase e, portanto, o conhecimento de si é tema de preocupação e de interesse nos adolescentes.

Portanto, tendo em vista o referido, "cuidado de si" será utilizado como o cuidado que consiste no conhecimento de si, voltar o olhar para si, examinar-se a si mesmo, modificando-se, assumindo uma atitude filosófica diante de si, com relação a si, aos outros e a sua existência. E perguntamos: é possível ser o mestre do cuidado? É possível despertar o cuidado de si no jovem adolescente?

Frente às dificuldades vivenciadas, ou seja, em como auxiliar o adolescente em suas angústias com relação a si ao mesmo tempo em que se propõe ensinar filosofia, este artigo tem em vista contribuir para a discussão do possível vínculo entre o cuidado de si e o professor estagiário no tocante a sua inserção na escola pública, tendo no fim, uma relação ética com o aluno.

\section{O Cuidado de si no ensino de filosofia}

"O homem pode converter-se no mais divino dos animais, sempre que se o eduque corretamente; converte-se na criatura mais selvagem de todas as criaturas que habitam a terra, em caso de ser mal- educado." (Platão, As Leis, 766 a.)

Em suas inúmeras interpretações, a filosofia enquanto cuidado de si é concebida como uma atividade em conformidade com um discurso filosófico que se leva a cabo para constituir uma forma de vida ou estética da existência. Esta vida é articulada em função de um discurso que tem a pretensão de servir como 
uma espécie de terapia em relação ao modo habitual de condução e gestão da vida. A filosofia assim compreendida é um método terapêutico com vínculo à prática de exercícios que tem como objetivo a transformação do eu e da personalidade de todo aquele que exercita-se, conduzido a uma modificação e melhora de si.

Quem conhece alguma parte do seu corpo só conhece algo de si mesmo, porém não se conhece ${ }^{3}$. E quem não se conhece tampouco poderá conhecer a arte que o deixa melhor, já que não sabe quem é. Esforça-te para te tornares cada vez mais bonito. Quer dizer, busca ser sempre melhor. Em nossa perspectiva, essa é a tarefa da educação, ou seja, além de por em prática aspectos técnicos operativos, trata-se também de investigar a melhor forma de aperfeiçoar tanto o discípulo quanto o mestre. Conhecer-se deve consistir numa busca constante tanto daquele que educa quanto daquele que exerce o papel de educando. Não se trata de um caminho fácil. Conquistar a si mesmo é fruto de um grande esforço.

A última afirmação acima faz menção à experiência de estágio realizada na escola, no período de julho a dezembro de 2015. O que queremos dizer com isto é que durante esse processo no qual adquire-se contato com os alunos dia após dia, não é tarefa fácil despertar neles o cuidado de si, tampouco conquistar a nós mesmos. Saliento que desenvolver o cuidado de si nos alunos é importante porque nesse aspecto envolve a nossa concepção de filosofia, bem como o sentido da filosofia no ensino médio enquanto professores de filosofia.

Reforçamos que é preciso que exista uma educação para pensar, mas um pensar filosófico através de uma educação que forneça os elementos essenciais para que os alunos através de uma postura crítica diante de si e da realidade em que vivam possam exercer a sua cidadania, pensando por si próprios de forma crítica e profunda. Esse é o desafio! Eis, aí, o sentido de a filosofia ajudar o sujeito a ver a realidade, levando-a a pensar de forma sistemática para que seja capaz de desvelar a realidade que o cerca, interpretá-la propondo soluções e alternativas.

Durante o período do estágio não é preciso ter uma definição de filosofia pronta e estática, pois assim limitaria não só o conceito de filosofia, mas também o interesse do aluno para com a mesma, ou seja, não deve-se privar o aluno de

${ }^{3} \mathrm{O}$ Primeiro Alcibiades, $132 \mathrm{c}$ 
descobrir e refletir sobre o que seja a filosofia. Por isso, sempre tenhamos em mente o que demonstra o professor Cabreira (2010) no seu livro "Diário de um filósofo no Brasil", onde afirma haver não uma filosofia, mas, uma pluralidade de filosofias: "Não tento aqui definir a filosofia, mas, pelo contrário, despojá-la de toda definição fixa, deixá-la ir o mais livre possível para ela mesma achar suas definições mais cabíveis, provisórias, celebradas ou desabonadas." (CABREIRA, 2010, p.16)

Partindo dessa compreensão plural da filosofia, não tentemos trabalhar com a delimitação propriamente dita do conceito de filosofia, mas despojá-la para se alcançar o exercício do conhecimento de si, pois este é um dos sentidos se não o mais importante que esta disciplina pode abrir e contribuir no Ensino médio, a saber: A capacidade de modificar, transformar e aperfeiçoar. Ademais, a adolescência é a fase de transformações e descobertas, eis aí o motivo da filosofia ser importante, pois ela pode contribuir para que o jovem, através do cuidado de si, descubra quem ele é e perceba suas modificações e, portanto, contribua para seu amadurecimento.

Com tudo isso, fica claro que demonstramos o quanto é importante que a filosofia não tenha apenas uma definição, o que a tornaria estática. Muito pelo contrário, pensamos que ela possa ser uma atividade espiritual e reflexiva, que através do exercício do pensamento possa contribui para que os alunos do Ensino médio amadureçam e mudem suas concepções mais íntimas.

De inúmeras maneiras encontra-se a tentativa de despertar o cuidado de si nos alunos. Contudo, as turmas de adolescentes em Ensino Médio, geralmente, caracterizam - se por serem agitadas, o que torna-se uma dificuldade. Não há, da parte dos alunos, paciência para as reflexões e muitas vezes percebe-se preguiça no desenvolvimento de textos, o que dificulta o desenvolvimento do cuidado de si, bem como cria dificuldades frente ao professor que deveria conduzir o aluno e de certo modo, governá-lo. Diante disso, o aluno não permite ser governado pelos professores, e quando utiliza-se o conceito "governar", refere-se a criar condições de diálogos e espaços de reflexões. Por que é tão difícil despertar o cuidado de si?

Há quem argumente que as crianças sejam filósofos, porém as crianças amadurecem, há o processo de crescimento biológico e as curiosidades passam a ser de outra natureza, é normal que percam o interesse por "filosofar", questionar, 
afinal existem tantas outras coisas além da filosofia. Assim, isso é natural e compreensível, pois quando as crianças deixam de serem crianças, outras curiosidades surgem e dentre delas começa-se o questionamento a como conduzir e o que fazer da vida, entra-se, então, na adolescência.

\section{A adolescência, cuidado de si e a (im)possibilidade de ser o mestre do cuidado}

O que é ser adolescente? O que sabemos sobre este estágio da existência humana angustiante e complicada? A adolescência para Tugendhat, por exemplo, é quando:

Surge a capacidade de enamorar-se. Quando uma pessoa se enamora seriamente, passa-se algo que pressupõe que é capaz de relacionar o que Ihe importa noutra pessoa com sua vida. Assim se entende que no mesmo momento em que as pessoas chegam a ser capazes de enamorar-se, também podem começar a ocupar-se com a vida e com a morte. Em crianças em geral não se encontra o que chamo de terceira ordem volitiva (TUGENDHT, 2002, p. 95)

Dito isso, o certo seria refletirmos de que maneira as crianças perguntam-se sobre o sentido da vida, e que essa não deve ser comparada da mesma maneira e intensidade como isso ocorre com os adolescentes. Há, sem dúvida, um grande processo entre o ser criança e o ser adolescente, a saber, crianças não cometem erros alegando a falta de sentido para a vida, isso é um problema que ocorre na adolescência. Nessa perspectiva, crianças não cuidam de si, visto que devem ser cuidadas por nós adultos, devem ser conduzidas; os adolescentes, por sua vez, estão aprendendo a cuidar-se, aprendendo a como dar sentido para suas vidas.

A tentativa da busca do cuidado de si com os alunos, ao mesmo tempo que pode ser válida, na medida em que a filosofia pode contribuir para saciar algumas das suas inquietações, não é tarefa fácil de realizar, devido à peculiaridade da adolescência. Não é fácil para um adolescente estabelecer algumas distinções razoáveis entre o conhecimento de si sobre alguns aspectos, a saber, o 
conhecimento de si como um ser humano, do ponto de vista social e político; o conhecimento de si pelo ponto de vista pessoal e psicológico; não é fácil o conhecimento de si mediante a fatos históricos, bem como, enfim, no sentido filosófico, que seria a parte de pensarmos do ponto de vista das nossas vidas como um todo.

Em algumas atividades realizadas em sala de aula com os alunos, pode-se perceber a dificuldade que eles possuem diante do examinar-se e modificar-se. Ademais, é notável a dificuldade dos adolescentes em lidar consigo mesmo: "Egoísta porque quero tudo pra mim e não gosto de compartilhar o que é meu, sou estressado porque praticamente tudo me estressa, principalmente esperar, sou desinteressado com algumas coisas que não gosto de fazer, preguiçoso e não gosto nem um pouco disso, porque me atrapalha muito e me considero 'reinento' demais com coisas que não quero e não gosto de fazer". Essa foi à resposta de um dos alunos do $2^{\circ}$ ano quando solicitado uma tarefa em que exigia-se justamente a reflexão sobre si e o cuidado de si. Ao mesmo tempo que percebe-se essa dificuldade, em muitos nota-se uma abertura para mudança e reflexão de si como nesse caso: "Mudar e pensar sobre si é difícil, sair da sua zona de 'conforto', mas eu já mudei bastante e continuo tentando mudar".

Que seja fácil ou difícil, o que é certo é que conhecendo-nos, ficaremos com condições de saber como cuidar de nós mesmos, o que não podemos saber se nos desconhecermos. ${ }^{4}$ A bondade deve ser buscada dentro do homem. A primeira obrigação desse é preocupar-se consigo mesmo, e seu autêntico "si mesmo" é sua alma. E aí reside a obrigação de conhecer a si mesmo.

No entanto, como já mencionamos na adolescência pequenas situações tornam-se uma tragédia e enquanto educador precisa-se ter muita paciência para despertar o cuidado de si. A dificuldade do educador de conduzir/governar o aluno sobre o cuidado de si reside muitas vezes pelo não conhecimento do que na verdade é a adolescência. E isso não ocorre apenas com os professores, os pais (até onde se pode observar) dos alunos na escola não conseguem conduzir o aluno para uma autoeducação e modificação de si, o que resulta em um grande problema, pois a família é fundamental no processo dessa fase da infância para

${ }^{4}$ O Primeiro Alcibíades, $129^{a}$. 
adolescência. Se os pais abdicam sua responsabilidade com relação ao adolescente que está aprendendo a cuidar de si, o adolescente é forçado a passar muito bruscamente por essa fase, tornando-se adulto muito rapidamente. É o que observa Winnicott:

O principal é que a adolescência é mais do que puberdade física, embora se baseie, sobretudo nesta. A adolescência implica crescimento, e esse crescimento leva tempo. E, enquanto o crescimento se encontra em progresso, a responsabilidade tem de ser assumida pelas figuras parentais. Se essas figuras abdicam, então os adolescentes têm de passar para uma falsa maturidade e perder sua maior vantagem: a liberdade de ter ideias e de agir segundo impulso. (WINNICOTT, 1975, p. 186)

A parte discente é uma parte importante a ser considerada na escola, sem a presença deles a escola não tem sentido algum, porém muito pouco se sabe deles ou sobre eles. Muito se fala dos alunos, ou como reclamações ou como elogios, mas muito pouco de nós ou os professores como um todo sabem sobre a adolescência enquanto etapa de desenvolvimento psico-biológico. Professores e funcionários de uma escola possuem uma convivência direta com os alunos, convivem de forma intersubjetiva, mas poucos destes de fato leram ou informaramse sobre a adolescência, pois antes de serem tratados como alunos, são adolescentes. Ou seja, essa fase complicada de descobertas, sonhos, fantasias e, sobretudo, a falsa maturidade que apresentam ter ou que pensam ter.

A adolescência implica crescimento, mudanças, esse crescimento leva tempo e precisa desenvolvimento. Com isso, a responsabilidade tem de ser assumida pelas figuras parentais, ou seja, os responsáveis dos alunos adolescentes. Se essas figuram abdicam, fogem da responsabilidade, então os adolescentes têm de passar para uma falsa maturidade e perder sua maior vantagem de agir por impulso. Dessa forma, não há a tentativa defender que os alunos possam ou devam ser grosseiros, ou ainda que devam agir com falta de educação com relação aos seus professores e aos funcionários das escolas, mas sim, que possuem falta de maturidade e por isso, necessitam do auxílio destes e ainda responsabilidade dos pais frente a eles. A imaturidade, segundo, Winnicott é uma 
parte preciosa da adolescência, e a cura para esta, é a passagem do tempo. Ademais, é uma fase preciosa quanto à excitação do pensamento. É o que percebe-se na seguinte citação:

\begin{abstract}
A imaturidade é uma parte preciosa da adolescência. Nela estão contidos os aspectos mais excitantes do pensamento criador, sentimentos novos e diferentes, ideias de um novo viver. A sociedade precisa ser abalada pelas aspirações daqueles que não são responsáveis. Se os adultos abdicam, o adolescente torna-se prematuramente, e por um falso processo, adulto. O conselho à sociedade poderia ser: por amor aos adolescentes, e a sua imaturidade, não thes permitam crescer e atingir uma falsa maturidade, transmitindo-lhes uma responsabilidade que ainda não é deles, mesmo que possam lutar por ela. (WINNICOTT, 1975, p 198)
\end{abstract}

Com a citação de Winnicott, percebe-se que os adolescentes estão em uma fase de excitação de pensamento. Esta fase é ótima para criação e recriação de ideias, visto que estes estão em mudanças, não somente com relação as seus corpos como parte física, mas também, mudanças de ideias e reavaliações de concepções.

Até então trabalhamos com uma das perspectivas propostas no artigo, o adolescente com relação ao cuidado de si. Ainda temos mais uma perspectiva a refletir, o estagiário diante do mesmo conceito. O homem deve submeter-se a si mesmo a exame, e Sócrates diz na Apologia: "Uma vida sem reflexão não merece ser vivida". Enquanto professor é necessário utilizar a autoeducação para o aprimoramento e a melhora de si. O professor aprende muito com aquele que ensina, descobre coisas sobre si mesmo que antes eram obscuras. As situações do dia-a-dia com alunos fazem com que necessitemos de modificação e aprimoramento de si, uma vez que precisamos ter responsabilidade para aquele que se ensina, pois temos uma relação ética com o aluno.

Descobrimos, por exemplo, que paciência é importante e o aprimoramento dela também. Além disso, as metodologias e aulas devem ser repensadas e isso exige um conhecimento de si. Essa relação mestre e discípulo exige, como foi 
mencionado em outro momento, um saber conduzir por parte do professor, saber governar. E só governa bem aquele que governa-se a si mesmo. Quando governase a si mesmo, o caminho é despertar no aluno o cuidado de si para que esse possa tornar-se cada vez mais autônomo com relação aos seus pensamentos, dúvidas e opiniões, e seja também governante de si mesmo.

\section{Conclusão}

Neste artigo relatou-se sobre o cuidado de si em Michel Foucault, com o objetivo de relacioná-lo com o estágio realizado na escola, no período de julho a dezembro de 2015. O cuidado de si, portanto, é e foi tomado neste artigo como a capacidade do sujeito de se autoeducar, modificando-se e aprimorando-se para tornarem-se mais belos. Essa perspectiva foi apresentada de duas maneiras, a primeira com relação ao jovem adolescente na medida que esse está em profunda transformação e é nessa fase que começa-se a reflexão sobre quem somos e o que fazemos para com nossa vida; e sobre a perspectiva do professor estagiário que deve-se aprimorar-se com relação as suas metodologias e aulas, bem como aprimorar-se enquanto ser humano para melhor atender as necessidades de seus alunos adolescentes.

A filosofia, então, sobre essa perspectiva apesar de não ter que ser definida, o que limita a curiosidade dos alunos, deve ser tratada como a possibilidade da descoberta e reflexão de si, visto que na adolescência, apesar de ser difícil despertar o cuidado de si, essa fase proporciona a reflexão sobre ele. Os adolescentes, portanto, não são adultos imaturos, mas estão passando por uma fase de amadurecimento e crescimento com suas dificuldades e alegrias específicas.

A escola é uma instituição criada na modernidade que tem a função de receber indivíduos de todos os tipos e etnias. Todavia, ela não consegue abarcar a todos, o que cria alguns problemas, tal como a falta de atenção para com os alunos. Os alunos reclamam da atenção ou da falta de atenção que a escola tem com eles. É preciso tomar decisões drásticas quanto a isso para conseguir abarcar as necessidades deles. 
O estágio em licenciatura também dá a perspectiva de quais são as possibilidades da futura profissão, pois o estágio é esperado tanto com empolgação tanto com ansiedade e angústia. Portanto, é preciso ter em mente que o estágio é um espaço de resistência. Resistências múltiplas diante da escola, das dificuldades da inserção na escola, de nossas limitações e precariedades e até mesmo sobre nossos conhecimentos com relação ao mundo capitalista avesso a paciência que o pensar requer. Mas, para manter-se resistente, há de se fazer algo mais, para além da vontade de resistir. Para se obter resistência há de se exercitar. Isso lembra-me Deleuze:

Acreditar no mundo é o que mais nos falta; nós perdemos completamente o mundo, nos desapossaram dele. Acreditar no Mundo significa principalmente suscitar acontecimentos, mesmo pequenos, que escapem ao controle, ou engendrar novos espaçostempos, mesmo de superfícies ou volume reduzidos (...). É ao nível de cada tentativa que se avaliam a capacidade de resistência ou, ao contrário, a submissão a um controle. (DELEUZE 1992, p.218) 


\section{Referências bibliográficas}

CABREIRA, Julio. Diário de um filósofo no Brasil. Unijuí, 2010.

DELEUZE, Gilles. Conversações 1972-1990. Rio de Janeiro: Ed. 34, 1992.

FOUCAULT, Michel. "O que é um filósofo?" Ditos escritos II. Rio de Janeiro: Forense Universitária, 2000.

FOUCAULT, Michel. A hermenêutica do sujeito. Curso dado em 1981-1982, Tradução de Márcio Alves da Fonseca e Salma Tannus. São Paulo: Martins fontes, 2006.

PLATÃO. Apologia de Sócrates. Trad. e apêndice de Maria Lacerda de Moura. Rio de janeiro, EDIOURO, 1985;

PLATÃO. Primeiro Alcibíades. Tradução de Carlos Alberto Nunes, 1975. P - 33 a 99

TUGENDHAT, Ernest. Não somos de arame rígido. Ed. Ulbra, 2002. 